\title{
Sensitivity analysis of a livestock odour dispersion model (LODM) to input parameters, Part 2: Meteorological parameters
}

\author{
Z. Yu ${ }^{1,2}$, H. Guo ${ }^{1, *}$ and C. Laguë ${ }^{3}$ \\ ${ }^{I}$ Department of Chemical and Biological Engineering, University of Saskatchewan, Saskatoon, SK, Canada \\ ${ }^{2}$ Golder Associates Ltd. Saskatoon, SK, Canada \\ ${ }^{3}$ Faculty of Engineering, University of Ottawa, Ottawa, ON, Canada \\ "Email: huiqing.guo@usask.ca \\ http://dx.doi.org/10.7451/CBE.2013.55.6.13
}

Yu, Z., H. Guo and C. Laguë. 2013. Sensitivity analysis of a livestock odour dispersion model (LODM) to input parameters, Part 2: Meteorological parameters. Canadian Biosystems Engineering/Le génie des biosystèmes au Canada 55: 6.13-6.23. The sensitivity of a livestock odour dispersion model (LODM) to its input meteorological parameters with respect to its output odour concentration and odour frequency was analyzed. Results showed that the effects of meteorological parameters on downwind odour concentrations and odour frequencies were different. The sensitivity of wind speed was from medium to high to odour concentration and low to high to odour frequency under different stability conditions. The wind direction and stability class had high sensitivity on both odour concentration and odour frequency. The sensitivity of ambient temperature was medium to model predicted odour concentration and low to medium to odour frequency. The sensitivity of mixing height is low while it is indifferent of solar radiation and cloud cover. The meteorological parameters in an order of decreasing importance would appear to be stability class, wind direction, wind speed, ambient temperature, cloud cover, mixing height, and radiation. Keywords: Livestock odor dispersion model, sensitivity analysis, wind speed, wind direction, stability class

La sensibilité d'un modèle de dispersion d'odeur (LODM) en fonction des paramètres météorologiques entrés a été analysée en ce qui à trait aux résultats obtenus de concentration d'odeur et de fréquence d'odeur. Les résultats ont montré que les effets des paramètres météorologiques sur les concentrations d'odeur et les fréquences d'odeur sous le vent étaient différents. La sensibilité de la vitesse des vents était de moyenne à élevée pour la concentration d'odeur et de faible à élevée pour la fréquence d'odeur sous différentes conditions de stabilité. La direction des vents et la catégorie de stabilité avaient une sensibilité élevée tant sur la concentration d'odeur que sur la fréquence d'odeur. La sensibilité de la température ambiante était moyenne pour la prédiction de la concentration d'odeur et faible à moyenne pour la fréquence d'odeur. La sensibilité de hauteur de mélange était faible tandis qu'il n'y a pas de différence associée à la radiation solaire ou au couvert nuageux. Les paramètres météorologiques, dans un ordre décroissant d'importance, semblent être la catégorie de stabilité, la direction des vents, la vitesse des vents, la température ambiante, le couvert nuageux, la hauteur de mélange et la radiation. Mots clés: modèle de dispersion des odeurs d'élevage, analyse de sensibilité, vitesse des vents, direction des vents, catégorie de stabilité.

\section{INTRODUCTION}

A livestock odour dispersion model (LODM) has been developed based on the theory of Gaussian fluctuating plume model (Yu et al. 2011a; 2011b). The main purpose of this model is to predict the occurrence frequency of certain level odour (e.g. $1 \mathrm{OU} / \mathrm{m} 3$ ) in an hour with the hourly mean input meteorological data. The hourly odour frequency is particularly important for livestock odour, since odour can cause nuisance and complain within a few seconds if the odour concentration is beyond its annoyance criteria (De Bree and Harssema 1987; Mussio et al. 2001). Hence, this model will help facilitate the application of air dispersion models in odour impact assessment, odour control technologies evaluation, and odour regulation. Sensitivity analysis is the analysis conducted to find out the variation of air dispersion models' output following the change of input parameters. It is necessary and valuable to conduct sensitivity analysis for a new model as part of the evaluation process (Horwedel et al. 1992). From the sensitivity analysis, the importance of the input parameters to the model can be found and the variations of the model output to certain input parameter can be explored. This approach can help to identify areas where further research is needed. LODM requires three kinds of input parameters: source parameters, surface parameters, and meteorological parameters. The sensitivity analysis of the first two kinds of parameters have been conducted and presented in the Part 1 of this study.

Meteorological parameters are very important to the model because they have great impact on odour dispersion in atmosphere. The input meteorological data of LODM consist of wind speed, wind direction, atmospheric stability class, ambient temperature, mixing height, solar radiation, and cloud cover. After conducting the sensitivity analysis of the STINK model, Smith (1993) pointed out that wind speed and stability class are very important factors that affect odour dispersion; however, wind direction was just moderately important. Meteorological sensitivity analysis has been conducted for a windows-based Gaussian plume model (Chastain and Wolak 1999) and a Gaussian Puff model (INPUFF2) (Guo et al. 2001) in modeling livestock 
odour dispersion. It gave no surprise results that the odour plume was wider and longer under more stable weather conditions and lower wind speed conditions. Xing et al. (2007) conducted sensitivity of two steady-state Gaussian plume dispersion models (ISCST3 and, AUSPLUME) and two non-steady-state puff models (CALPUFF and INPUFF-2) under steady-state weather conditions. It was concluded wind speed and stability class had great impact on all four models; ambient temperature had some impact on INPUFF-2 but its impact was very limited on other models; wind direction had some impact on all four models near the source, and this impact decreased with increasing distance. Faulkner et al. (2008) compared the sensitivity of two dispersion models (AERMOD and ISCST3) to input parameters for a rural ground-level area source. AERMOD is a USEPA preferred steady-state plume model that incorporates air dispersion based on planetary boundary layer turbulence structure and scaling concepts (USEPA 2004). Results showed that concentrations predicted using ISCST3 were sensitive to changes in wind speed, temperature, solar radiation, and mixing heights below $160 \mathrm{~m}$; AERMOD was sensitive to changes in wind speed, temperature, and cloud cover. It also showed that AERMOD was sensitive to small changes in wind speed.

The objective of this paper is to analyze the sensitivity of LODM predicted odour concentrations and frequencies to its input meteorological parameters, i.e. wind speed, wind direction, ambient temperature, stability class, mixing height, solar radiation, and cloud cover.

\section{MATERIALS AND METHODS}

\section{Location of simulations}

A virtual point source was placed at $150 \mathrm{~km}$ west of Saskatoon, Saskatchewan, Canada (52.167 N, 108.687 W), where a typical swine farm located. The time zone of this location is identified by -6 hours from GMT. The wind speeds were assumed to be measured at height $10 \mathrm{~m}$ above the ground level.

\section{LODM}

LODM is an odour dispersion model developed to predict hourly odour concentration and hourly odour frequency downwind the livestock odour source with the input of routine hourly averaged meteorological data. The model was based on the Gaussian fluctuating plume model (Yu et al. 2011a). The hourly odour frequency is estimated by a weighted odour exceeding half width method adapted from Hogström (Högström 1972). The prediction of hourly odour frequency was from horizontal and vertical distributions of the centroid of a plume within which the odour concentration equals to or exceeds the defined odour threshold (e.g. $1 \mathrm{OU} / \mathrm{m} 3$ ). The plume is confined between a maximum height and the ground in order for the receptor to reach the plume vertically. The distance between the ground level and the maximum height is divided into $\mathrm{N}$ equal spaces ( $N=100$, in LODM) in order to estimate the weighted odour exceeding half width, which will then be used to estimate the hourly odour frequency. Therefore, a pseudo short averaging period is found by dividing 1 hour by $\mathrm{N}$, which results in $36 \mathrm{~s}$. A stability index was adapted in LODM, which was defined as:

$$
s=\left(\frac{\partial \theta}{\partial z} / u_{f}^{2}\right) \cdot 10^{5}
$$

in which $\partial \theta / \partial z$ is the vertical gradient of potential temperature at the level of the plume centre, $\mathrm{K} / \mathrm{m}$; $\mathrm{u}_{\mathrm{f}}$ is the wind speed at the top of friction layer, $\mathrm{m} / \mathrm{s}$. Both parameters cannot be obtained directly from routinely observed meteorological data. The methods used to estimate the vertical profile of wind speed and vertical gradient of potential temperature, which determine the Hogstrǒm stability parameter (s) are following those used in AERMED model (USEPA 2004). The planetary boundary layer (PBL) was distinguished as convective boundary layer (CBL) and stable boundary layer (SBL). Cloud cover or solar radiation data were required in LODM to estimate the parameters such as fiction velocity, MoninObuhkov length, friction temperature, and sensible heat that represent the CBL or SBL. When cloud cover or solar radiation data are not available, LODM uses a simple method to covert the Passquil-Gifford (P-G) stability categories into solar radiations or cloud covers.

Surface wind speed, cloud cover or solar radiation determines the P-G stability class. When the P-G stability categories are originally defined, surface wind speed and insolation at daytime and cloud cover in nighttime were used (USEPA 2000). The atmospheric stability increases from stability class A to F. Another method used to determine P-G stability class is solar radiation/delta-T (SRDT) (USEPA 2000), which uses the surface layer wind speed in combination with measurements of total solar radiation during a day and a low-level vertical temperature difference $(\Delta \mathrm{T})$ at night.

Combined these two methods, the P-G stability categories can be determined from cloud cover at nighttime and solar radiation in daytime. Using the average solar radiation or cloud cover to represent the values of each category, the relationship between P-G stability categories and wind speed, solar radiation or cloud cover can be achieved and listed in Table 1 . In Table 1, R0 is the clear sky solar radiation of the current hour. When R0 is less than the upper bound of the range, the average is taken by R0 and the lower bound of the range. For example, when wind speed is less than $2 \mathrm{~m} / \mathrm{s}$, for stability class B, the solar radiation should be in the range of 175 to $675 \mathrm{~W} / \mathrm{m}^{2}$. If R0 is greater than $675 \mathrm{~W} / \mathrm{m}^{2}$, the average value will be 425 $\mathrm{W} / \mathrm{m}^{2}$; while if R0 is less than $675 \mathrm{~W} / \mathrm{m}^{2}$, the average value will be $(\mathrm{R} 0+175) / 2 \mathrm{~W} / \mathrm{m}^{2}$ instead.

\section{Sensitivity analysis}

The sensitivity of estimates of odour concentration and odour frequency to a particular variable/parameter is the change in the estimates with respect to a change in the value of the parameter while keeping all other parameters constant (Smith 1993). The sensitivity of wind speed, ambient temperature, mixing height, solar radiation, and 
cloud cover was expressed as an elasticity, S, which is defined as the percentage change in the concentration or frequency for a $1 \%$ change in the parameter value. The average sensitivity was determined using the sensitivity index as cited by Smith (1993).

$$
\mathrm{S}_{\mathrm{av}}=\frac{100}{\mathrm{~N} \Delta} \sum_{1}^{\mathrm{N}} \frac{\mathrm{C}_{\mathrm{ni}}-\mathrm{C}_{\mathrm{ci}}}{\mathrm{C}_{\mathrm{ci}}}
$$

where $\mathrm{N}$ is the number of points (odour concentration or odour frequency) in the model output; $\Delta$ is the absolute change in the parameter value expressed as a percentage of its control value; $C_{n i}$ is the new value of the concentration or frequency for ith point with a changed value of the input parameter; $\mathrm{C}_{\mathrm{ci}}$ is the corresponding value at $\mathrm{i}^{\text {th }}$ point in the control simulation.

However, for the sensitive analysis of the stability class, a slightly different index was defined as:

$$
\mathrm{S}_{\mathrm{av}}=\frac{100}{\mathrm{~N}} \sum_{1}^{\mathrm{N}} \frac{\mathrm{C}_{\mathrm{ni}}-\mathrm{C}_{\mathrm{ci}}}{\mathrm{C}_{\mathrm{ci}}}
$$

which indicates the average concentration or frequency changes in $\%$ for the change in stability class. For wind direction, the index was defined as:

$$
\mathrm{S}_{\mathrm{av}}=\frac{100}{\mathrm{~N} \Delta^{\prime}} \sum_{1}^{\mathrm{N}} \frac{\mathrm{C}_{\mathrm{ni}}-\mathrm{C}_{\mathrm{ci}}}{\mathrm{C}_{\mathrm{ci}}}
$$

in which, $\Delta^{\prime}$ is the change of wind direction in degree angle $\left({ }^{\circ}\right)$. Therefore, $S_{a v}$ is the concentration or frequency change in $\%$ for per degree change in wind direction.

When calculating the elasticity value, the receptors on which the predicted hourly odour concentration less than $0.1 \mathrm{OU} / \mathrm{m} 3$ were excluded to avoid the inappropriately large elasticity values. The sensitivity of the model predicted odour concentration and frequency to input parameters can be rated as: high $(|\mathrm{S}|>0.5)$, medium $(0.1<$ $|\mathrm{S}|<0.5)$, low $(0.01<|\mathrm{S}|<0.1)$, and indifferent $(|\mathrm{S}|<$ 0.01 ), in which $|\mathrm{S}|$ is the absolute value of $\mathrm{S}$.

The odour concentrations and odour frequency at the 231 downwind receptors that cover the downwind area of $1000 \mathrm{~m}$ width and $5000 \mathrm{~m}$ length as shown in Fig. 1 were estimated to conduct the sensitivity analysis. A base case was set as shown in Table 2 to reflect the typical setting of modelling a livestock odour source as point source. In order to simplify the sensitivity analysis, a simple point source with a stack height of $2 \mathrm{~m}$, a stack diameter of $3 \mathrm{~m}$, an exit velocity of $0.5 \mathrm{~m} / \mathrm{s}$, and an exit temperature of $22^{\circ} \mathrm{C}$ was utilized to represent the livestock odour source.

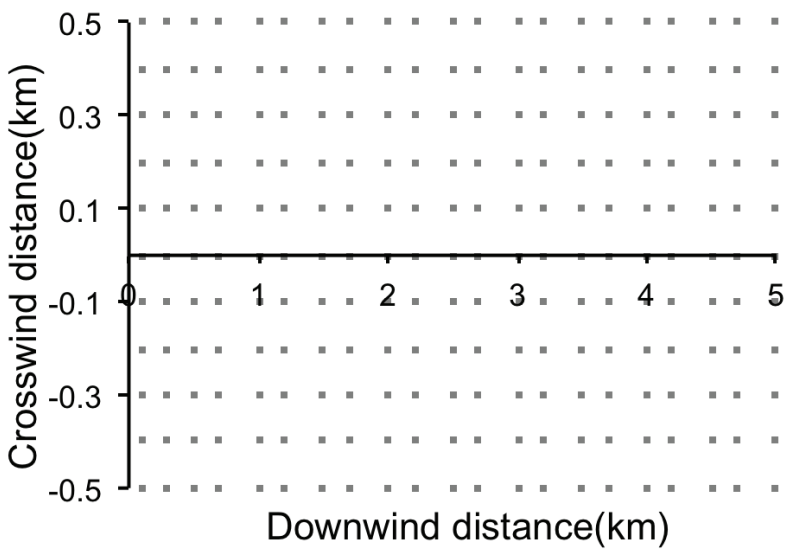

Fig. 1. Layout of 231 downwind receptors (each symbol represents a receptor with a height of $1.5 \mathrm{~m}$ ).

The emission rate of a typical swine barn in Saskatchewan varied from 219,693 OU/s to $967,556 \mathrm{OU} / \mathrm{s}$ during the warm season (May to Oct) (Guo et al. 2006), therefore the base emission rate in the simulation was set to be $500,000 \mathrm{OU} / \mathrm{s}$. The base of surface parameters was selected for grassland in summer season (USEPA 2004). The base of meteorological parameters such as ambient temperature, wind speed, wind direction, and mixing height and the variations can be also found from Table 2 . The elasticity (S) for each meteorological parameter was calculated. The changes in average concentration and frequency with the changing input parameter were also calculated. The changes of centerline odour concentration and odour frequency with the changes of input parameters were also plotted to demonstrate the sensitivity of input parameter on centerline odour concentration and odour frequency.

\section{RESULTS}

\section{Wind speed}

Effects of wind speed on downwind odour concentration and odour frequency are threefold. First, odour concentration is inversely related to the average wind speed at the stack height, which is derived from the reference wind speed. Since the odour frequency is estimated from the weighted odour exceeding half width method, which involves the calculation of odour concentrations, odour frequency is directly related to wind

Table 1. Representative solar radiation or cloud cover values for different P-G stability class.

\begin{tabular}{llllll}
\hline \multirow{2}{*}{ Wind speed } & \multicolumn{2}{l}{ Solar radiation, W/m $\mathrm{m}^{2}$} & \multicolumn{2}{l}{ Cloud cover } \\
\cline { 2 - 6 } & $\mathrm{A}$ & $\mathrm{B}$ & $\mathrm{C}$ & $\mathrm{E}$ & $\mathrm{F}$ \\
\hline$<2$ & $\left(\mathrm{R}_{0}+675\right) / 2$ & 425 or $\left(\mathrm{R}_{0}+175\right) / 2$ & - & - & - \\
$2-3$ & $\left(\mathrm{R}_{0}+925\right) / 2$ & 800 or $\left(\mathrm{R}_{0}+675\right) / 2$ & 425 or $\left(\mathrm{R}_{0}+175\right) / 2$ & $6 / 8$ & $3 / 16$ \\
$3-5$ & - & $\left(\mathrm{R}_{0}+675\right) / 2$ & 425 or $\left(\mathrm{R}_{0}+175\right) / 2$ & $3 / 16$ & - \\
$5-6$ & - & - & $\left(\mathrm{R}_{0}+675\right) / 2$ & - & - \\
$\gg 6$ & - & - & $\left(\mathrm{R}_{0}+925\right) / 2$ & - & -
\end{tabular}

A, B, C, E, F: P-G stability class categories; $\mathrm{R}_{0}$ : clear sky solar radiation. 
Table 2. Input parameters and there variations for sensitivity analysis.

\begin{tabular}{lll}
\hline Input parameter & Base case & Variation \\
\hline Source parameters & $5 \cdot 10^{5} \mathrm{OU} / \mathrm{s}$ & Constant \\
Emission rate & $2 \mathrm{~m}$ & Constant \\
Stack height & $3 \mathrm{~m}$ & Constant \\
Stack diameter & $0.5 \mathrm{~m} / \mathrm{s}$ & Constant \\
Exit velocity & $22^{\circ} \mathrm{C}$ & Constant \\
Exit temperature & & \\
Surface parameters & $0.1 \mathrm{~m}$ & Constant \\
Surface roughness & 0.18 & Constant \\
Albedo & 0.8 & Constant \\
Bowen ratio & & \\
Meteorological parameters & $20^{\circ} \mathrm{C}$ & $10,20^{*}, 30^{\circ} \mathrm{C}$ \\
Ambient temperature & $2.5 \mathrm{~m} / \mathrm{s}$ & Stability class C and D: $2,4 *, 6,8,10 \mathrm{~m} / \mathrm{s}$ \\
Wind speed & $90^{\circ}$ & Stability class E: $2,3,4 *, 5 \mathrm{~m} / \mathrm{s}$ \\
Wind direction & $\mathrm{C}, \mathrm{D}$, and E & $90^{\circ *}, 91^{\circ}, 92^{\circ}, 95^{\circ}, 100^{\circ}$ \\
Stability Class & $1000 \mathrm{~m}$ & $\mathrm{~A}, \mathrm{~B}, \mathrm{C}, \mathrm{D}, \mathrm{E}, \mathrm{F}$ \\
Mixing height & $\mathrm{N} / \mathrm{A}$ & $500,1000^{*}, 1500 \mathrm{~m}$ \\
Cloud cover & N/A & $0.1,0.2,0.3,0.4,0.5^{*}, 0.6,0.7,0.8,0.9,1$ \\
Solar radiation & $100,200,300,400,500^{*}, 600,700,800,900,1000 \mathrm{~W} / \mathrm{m}$ \\
\hline
\end{tabular}

* marks the control values used to calculate the elasticity index.

speed as well. Second, the reference wind speed is one of the determining factors of atmospheric stability. Therefore, it is an important factor for the calculation of the dispersion coefficients. Third, the wind speed is also a decisive factor of plume rise, thus it will affect the odour concentrations and odour frequencies downwind.

As seen from Figs. 2 to 5, under unstable condition $(\mathrm{SC}=\mathrm{C})$ and neutral condition $(\mathrm{SC}=\mathrm{D})$, the centerline

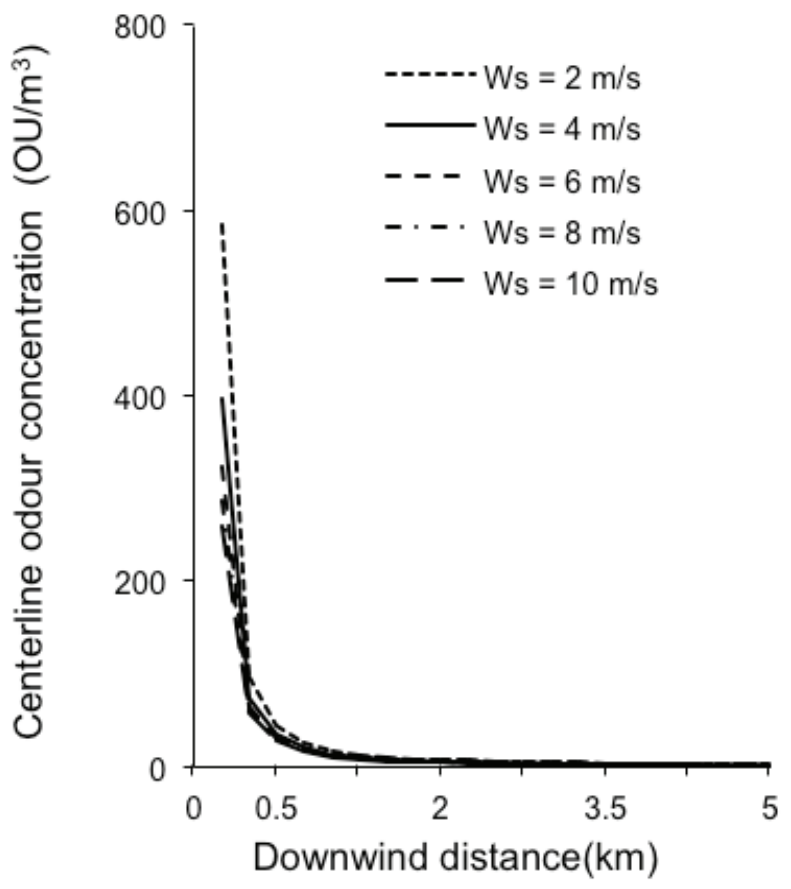

Fig. 2. Centerline odour concentrations for different wind speeds (Ws) under unstable conditions $(\mathrm{SC}=\mathrm{C})$. odour concentrations and odour frequencies decreased with the increase of wind speed. Under stable condition $(\mathrm{SC}=\mathrm{E})($ Fig. 6), when the wind speed was greater than 2 $\mathrm{m} / \mathrm{s}$, the centerline odour concentration decreased with the increase of wind speed. When the wind speed was $2 \mathrm{~m} / \mathrm{s}$, the centerline odour concentration increased until a maximum value was reached and then it decreased with distance. Under stable condition, the odour frequency for

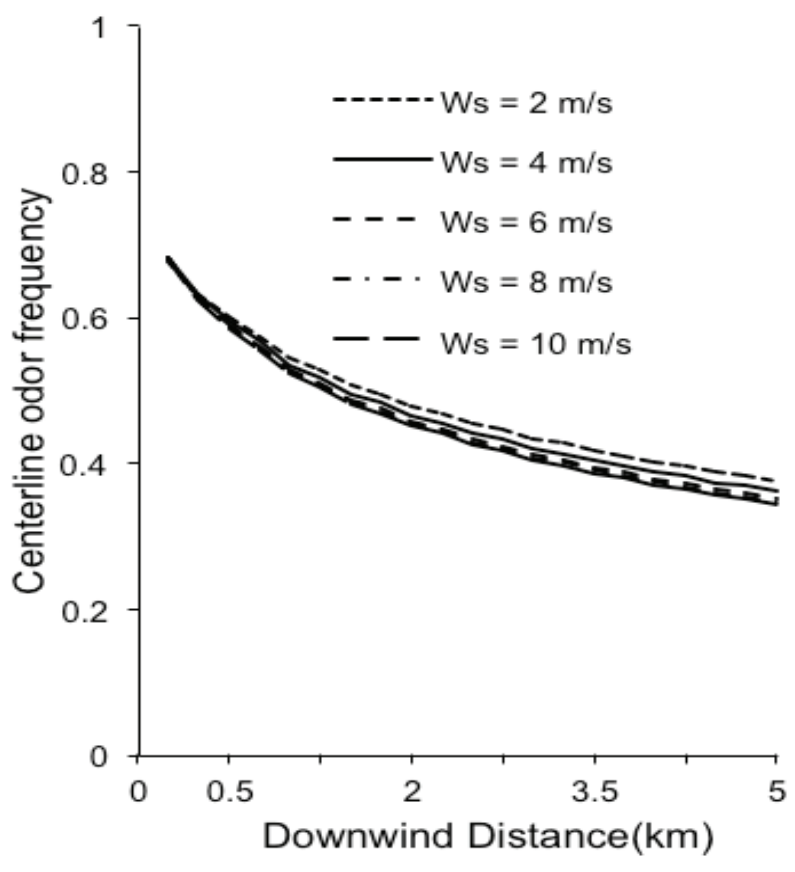

Fig. 3. Centerline odour frequencies for different wind speeds (Ws) under unstable conditions $(\mathrm{SC}=\mathrm{C})$. 
Table 3. Sensitivity analysis of odour concentration and frequency to exit velocity with a control value of $0.5 \mathrm{~m} / \mathrm{s}$.

\begin{tabular}{|c|c|c|c|c|c|c|c|c|c|}
\hline \multirow{2}{*}{ Stability } & \multirow{2}{*}{ Change, $\%$} & \multicolumn{4}{|c|}{ Concentration } & \multicolumn{4}{|c|}{ Frequency } \\
\hline & & Ave. C Change, & $\mathrm{S}(0.5)$ & $\mathrm{S}(5)$ & S(ave) & Ave. F & $\mathrm{S}(0.5)$ & $\mathrm{S}(5)$ & S(ave) \\
\hline \multirow{4}{*}{ Unstable } & -50 & 28.8 & 0.45 & 0.28 & 0.32 & 2.9 & 0.02 & 0.08 & 0.06 \\
\hline & +50 & -12.9 & -0.21 & -0.18 & -0.18 & -2.2 & -0.03 & -0.06 & -0.05 \\
\hline & +100 & -19.9 & -0.17 & -0.14 & -0.14 & -3.6 & -0.03 & -0.05 & -0.04 \\
\hline & +150 & -24.6 & -0.14 & -0.11 & -0.12 & -4.5 & -0.02 & -0.04 & -0.03 \\
\hline \multirow{4}{*}{ Neutral } & -50 & 67.7 & 1.43 & 1.47 & 1.46 & 10.1 & 0.11 & 0.27 & 0.25 \\
\hline & +50 & -28.5 & -0.58 & -0.58 & -0.58 & -7.0 & -0.09 & -0.18 & -0.17 \\
\hline & +100 & -44.3 & -0.45 & -0.45 & -0.45 & -12.4 & -0.08 & -0.16 & -0.15 \\
\hline & +150 & -54.3 & -0.37 & -0.37 & -0.37 & -16.9 & -0.07 & -0.15 & -0.13 \\
\hline \multirow{3}{*}{ Stable } & -50 & 236.0 & 1.28 & 9.14 & 7.39 & -66.6 & -1.57 & -1.57 & -1.37 \\
\hline & -25 & 28.8 & -1.01 & -1.07 & -1.05 & 2.1 & 0.09 & 0.09 & -0.11 \\
\hline & +25 & -22.0 & -1.70 & -1.76 & -1.75 & -2.6 & 0.11 & 0.11 & -0.24 \\
\hline
\end{tabular}

Ave. C Change, \%: percentages of averaged changes of odour concentration; Ave. F Change, \%: percentages of averaged changes of odour frequency; S (0.5): elasticity values calculated at downwind distances of $0.5 \mathrm{~km} ; \mathrm{S}(5)$ : elasticity values calculated at downwind distances of $5 \mathrm{~km}$.

wind speed $2 \mathrm{~m} / \mathrm{s}$ is much lower than wind speed of 3,4 , and $5 \mathrm{~m} / \mathrm{s}$ (Fig. 7). When wind speed increased from 3 to 5 $\mathrm{m} / \mathrm{s}$ under stable condition, the odour frequency increased at distance close to the source (around $1.5 \mathrm{~km}$ ), and then it decreased with the increase of wind speed.

The average changes of odour concentrations and odour frequencies and elasticity values were shown in Table 3. The average changes of odour frequency were $2.9 \%, 10.1 \%,-66.6 \%$ when the wind speed decreased from 4 to $2 \mathrm{~m} / \mathrm{s}$ respectively under unstable, neutral, and stable conditions. Under unstable condition, the averaged elasticity values for odour concentrations were -0.12 , $0.14,-0.18$, and 0.32 when wind speed changed from $4 \mathrm{~m} / \mathrm{s}$ to $2,6,8$, and $10 \mathrm{~m} / \mathrm{s}$. Based on the rating, the sensitivity was medium. The absolute elasticity values for odour concentration under neutral condition were between 0.37 and 1.46 , thus the sensitivity was medium to high. Under stable condition, for odour concentration the absolute elasticity values were $1.05,1.75$, and 7.39 , the sensitivity was high. For odour frequency, the model sensitivity to wind speed is low under unstable condition, medium under neutral condition, medium to high under stable condition.

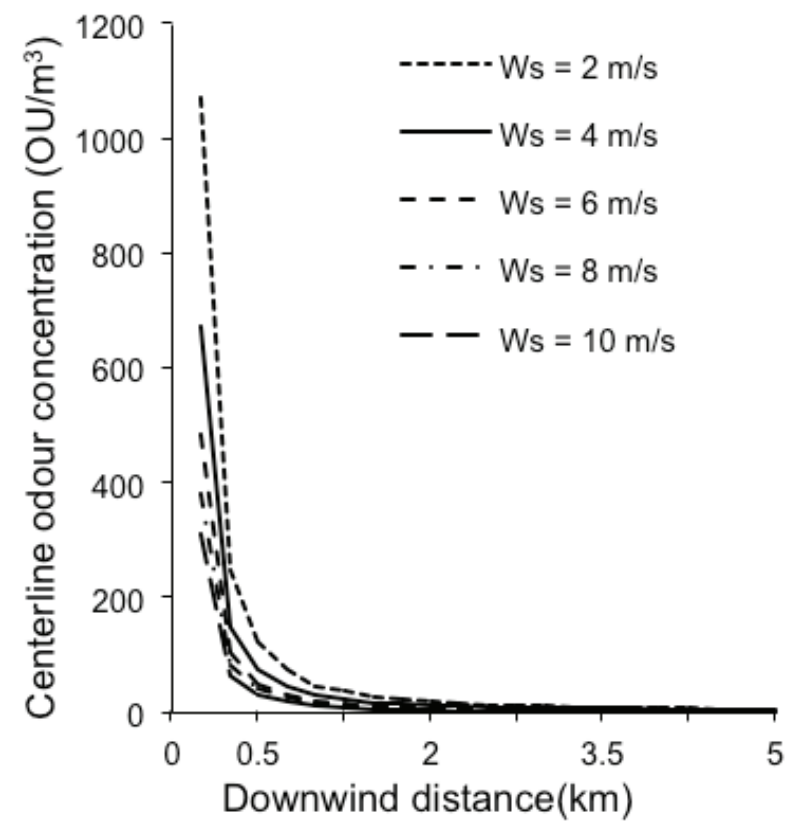

Fig. 4. Centerline odour concentrations for different wind speeds (Ws) under neutral conditions $(\mathrm{SC}=\mathrm{D})$.

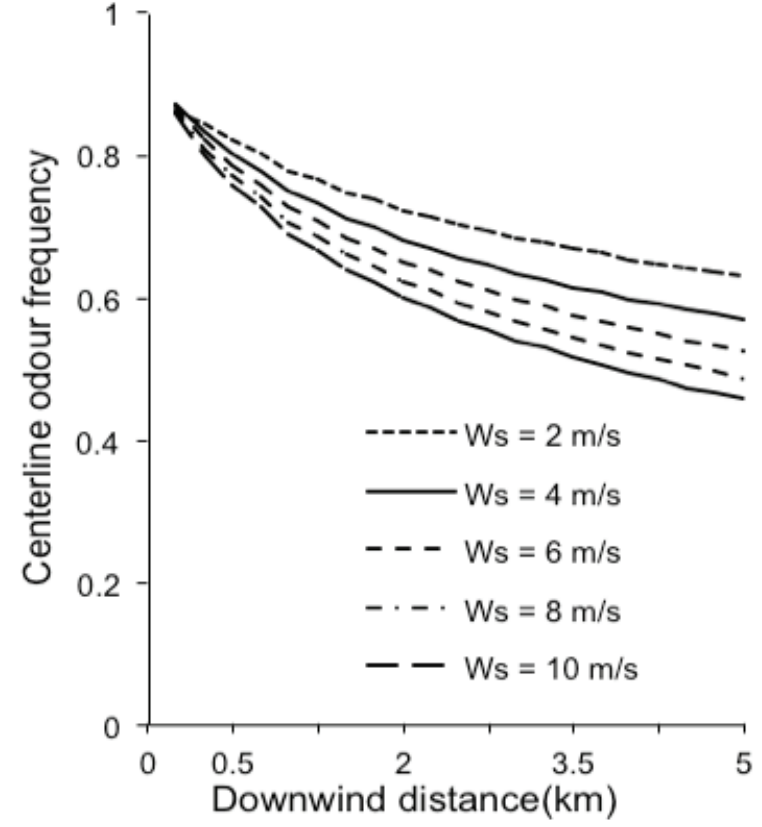

Fig. 5. Centerline odour frequencies for different wind speeds (Ws) under neutral conditions $(\mathbf{S C}=\mathbf{D})$. 
Table 4. Sensitivity analysis of odour concentration and frequency to wind direction with a control value of $90^{\circ}$.

\begin{tabular}{|c|c|c|c|c|c|c|c|c|c|}
\hline \multirow{2}{*}{ Stability } & \multirow{2}{*}{$\begin{array}{c}\text { Wind } \\
\text { direction }\end{array}$} & \multicolumn{4}{|c|}{ Concentration } & \multicolumn{4}{|c|}{ Frequency } \\
\hline & & Ave. C & $\mathrm{S}(0.5)$ & $\mathrm{S}(5)$ & S(ave) & Ave. F & $\mathrm{S}(0.5)$ & $\mathrm{S}(5)$ & S(ave) \\
\hline \multirow{4}{*}{ Unstable } & 1 & -0.4 & 1.56 & -0.93 & 0.17 & -0.5 & 1.27 & -0.92 & 0.12 \\
\hline & 2 & -1.1 & 3.11 & -1.85 & 0.33 & -1.4 & 2.54 & -1.84 & 0.23 \\
\hline & 5 & -7.1 & 7.73 & -4.26 & 0.81 & -9.4 & 6.20 & -4.29 & 0.53 \\
\hline & 10 & -21.7 & 14.70 & -6.37 & 1.52 & -28.4 & 11.34 & -6.41 & 0.90 \\
\hline \multirow{4}{*}{ Neutral } & 1 & -0.2 & 8.10 & -0.52 & 2.13 & 6.0 & -0.61 & 16.53 & 1.52 \\
\hline & 2 & -2.2 & 16.89 & -1.11 & 4.25 & 12.3 & -1.31 & 14.72 & 2.98 \\
\hline & 5 & -11.8 & 54.51 & -3.64 & 10.50 & 35.6 & -3.89 & 6.59 & 6.85 \\
\hline & 10 & -31.8 & 191.03 & -7.24 & 20.58 & 94.3 & -7.22 & -4.97 & 10.80 \\
\hline \multirow{4}{*}{ Stable } & 1 & -0.1 & 8.12 & -0.52 & 2.13 & -0.5 & 6.58 & -0.61 & 1.65 \\
\hline & 2 & -2.0 & 16.94 & -1.11 & 4.26 & -1.6 & 13.61 & -1.31 & 3.25 \\
\hline & 5 & -10.1 & 54.73 & -3.64 & 10.52 & -11.0 & 41.04 & -3.89 & 7.68 \\
\hline & 10 & -27.8 & 192.19 & -7.24 & 20.65 & -35.6 & 121.66 & -7.21 & 13.28 \\
\hline
\end{tabular}

Ave. C Change, \%: percentages of averaged changes of odour concentration; Ave. F Change, \%: percentages of averaged changes of odour frequency; $\mathrm{S}(0.5)$ : elasticity values calculated at downwind distances of $0.5 \mathrm{~km} ; \mathrm{S}(5)$ : elasticity values calculated at downwind distances of $5 \mathrm{~km}$.

\section{Wind direction}

Figures 8 and 9 and Table 4 revealed the model sensitivity of odour concentration and odour frequency to wind direction. The odour concentrations and odour frequencies were decreased with the increasing angles of the wind direction. Under stable condition, when wind direction changed from $90^{\circ}$ to $91^{\circ}$, the averaged odour concentration and odour frequency changes were $-0.1 \%$ and $-0.5 \%$ and the averaged elasticity values were 2.13 and 1.65 ; when wind direction changed from $90^{\circ}$ to $100^{\circ}$, the averaged

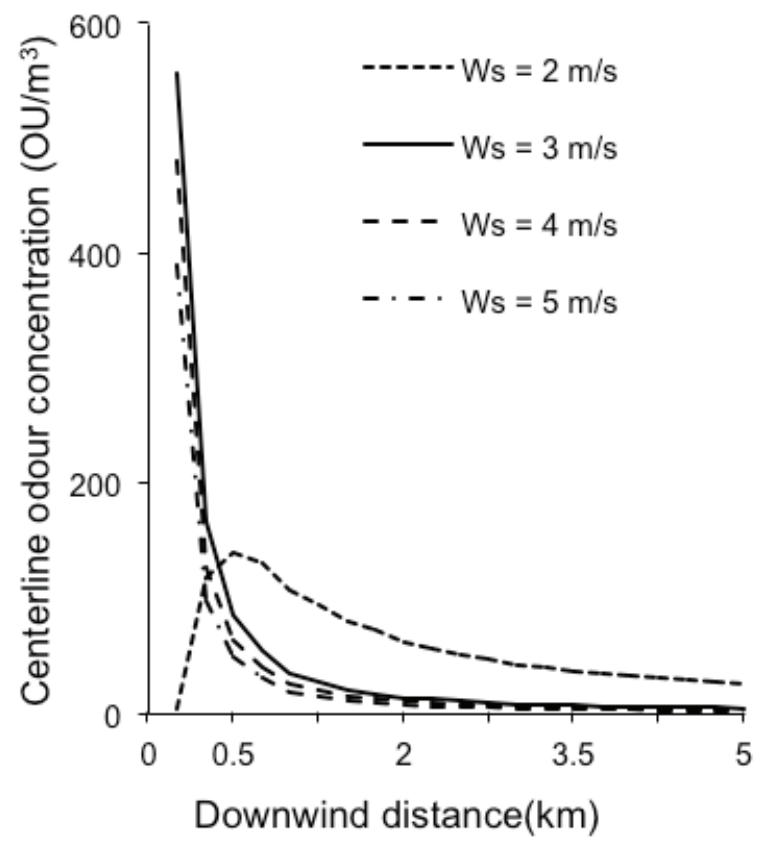

Fig. 6. Centerline odour concentrations for different wind speeds (Ws) under stable conditions $(\mathrm{SC}=\mathbf{E})$. elasticity values were 20.65 and 13.28 for odour concentration and odour frequency. Under unstable condition, the sensitivity is smaller than neutral and stable conditions. This can be explained by the fact that the odour plume is wider under unstable condition than under other conditions. The change of wind direction will cause changes in the distance between the receptors and the source and the crosswind distance between the receptors and the centreline of the plume. Due to the smaller dispersion coefficient under unstable condition than other

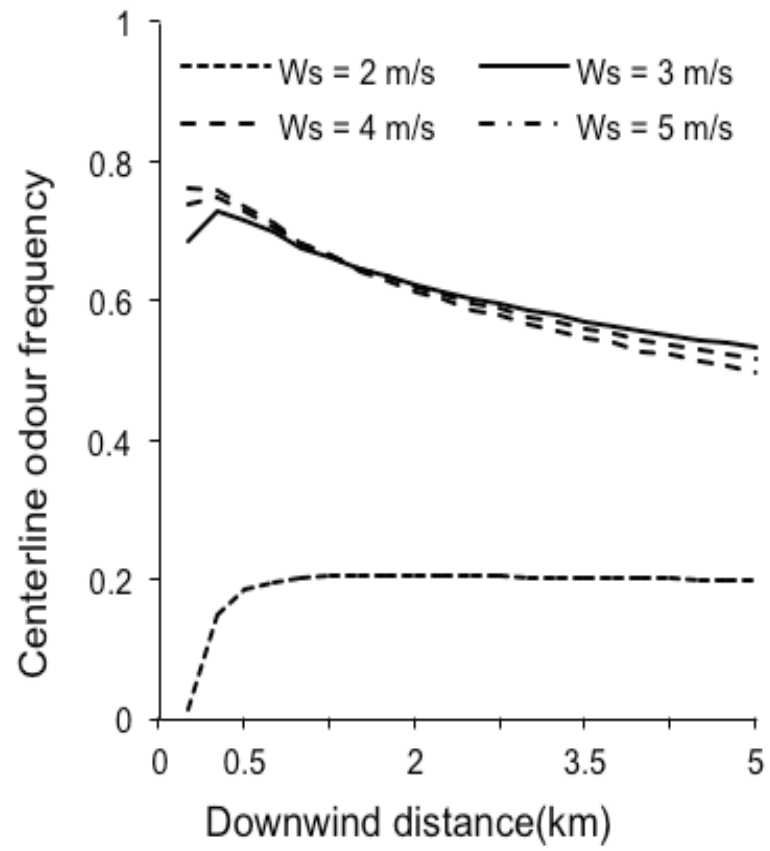

Fig. 7. Centerline odour frequencies for different wind speeds $(W s)$ under stable conditions $(\mathrm{SC}=\mathrm{E})$. 


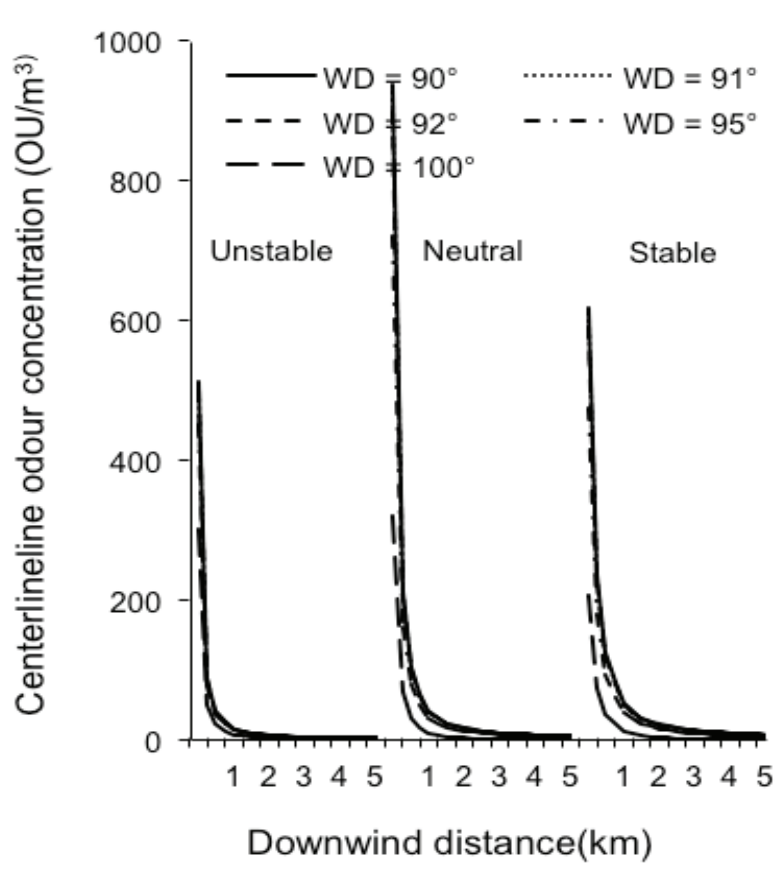

Fig. 8. Centerline odour concentrations for different wind directions (WD).

conditions, which results in wider odour plume, the changes of downwind distance and crosswind distance will have smaller effects on odour concentration and odour frequency. Overall, the sensitivity of wind direction is high. The wind direction has high effects on model predicted odour concentration and odour frequency. Yet, the wind direction is frequently shifting during the hour. The estimation of averaged wind direction is critical due to the high sensitivity of wind direction on model.

\section{Stability class}

When solar radiation or cloud cover data are unavailable, the model will convert the stability class into representative solar radiation or cloud cover to derive parameters in the PBL. Under unstable condition, the Hogstrǒm dispersion coefficient is irrelevant to stability; however, the stability class has effect on the wind speed profile to derive the wind speed at the stack height from the reference height. Therefore the odour concentrations and odour frequencies are similar under unstable conditions (A, B, and C) as seen in Figs. 10 and 11. As expected, the mean odour concentrations were larger for more stable conditions (Fig. 10) except for very stable condition $(\mathrm{SC}=\mathrm{F})$ under which at closed distance $(0.3$ $\mathrm{km})$ to the source, odour concentrations were small. The centerline odour frequency decreased when stability changed from neutral to stable and to more stable (Fig. 11 ), which is unusual as it is generally known that with the more stable atmospheric condition, the higher odour concentration and higher odour frequency would be observed. In the weighted odour exceeding half width method that was adapted in LODM, the odour frequency

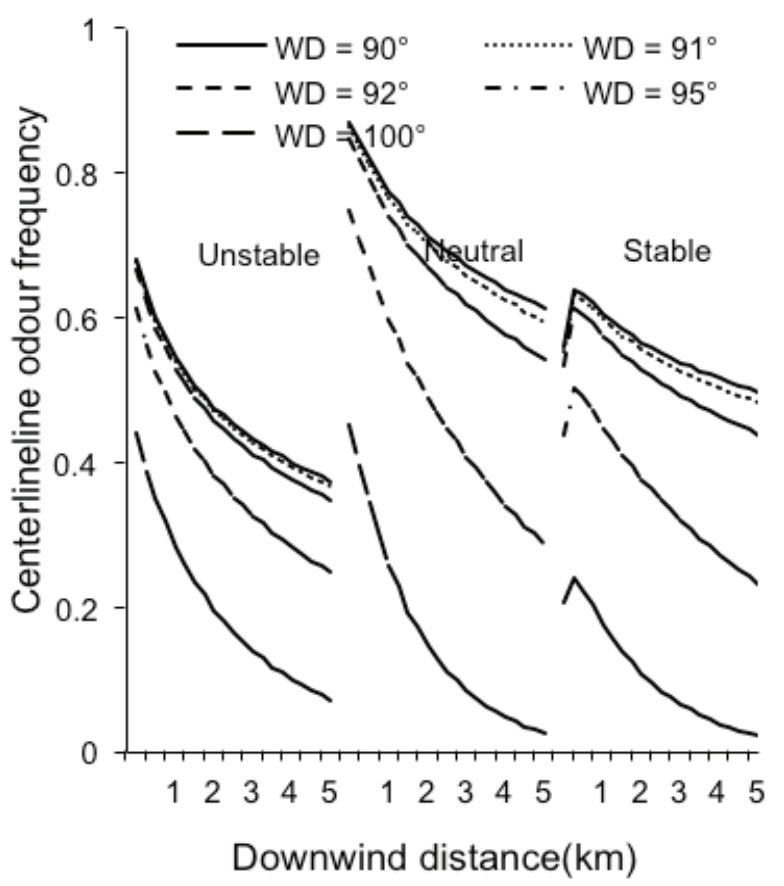

Fig. 9. Centerline odour frequencies for different wind directions (WD).

was determined by the width of the odour plume and the position distribution of the plume. With the increase of stability, the odour plume becomes narrower and it is highly possible that the odour frequencies at some receptors decreased.

Guo et al. (2005) studied the impact of weather conditions including wind speed and atmospheric stability on odour occurrence with the data reported by resident observers living within $8.6 \mathrm{~km}$ from three intensive swine farms in Saskatchewan, Canada. The results showed most odour events $(61.0 \%)$ were detected under neutral atmospheric stability class D. The odour events frequency was higher than the occurrence frequency of neutral conditions during the measurement periods of $60.6 \%$. Only $16.7 \%$ were detected under stable atmospheric conditions, which was lower than the occurrence frequency of stable stability classes (E and F) during the measurement periods of $17.2 \%$. Their finding was to some degree consistent with the simulation results from this study. The phenomenon that hourly odour frequencies were higher under neutral stability conditions than under stable stability conditions has great practical uses. However, more studies need to be done to verify this finding.

As seen from Table 5, when the stability class changed from A to B the averaged elasticity values for odour concentration and odour frequency were 0.23 and 0.05 , while the values are 0.40 and 0.07 when stability class changed from $\mathrm{B}$ to $\mathrm{C}$. The sensitivity of unstable stability class was medium for odour concentration and low for odour frequency. While the stability class changed 


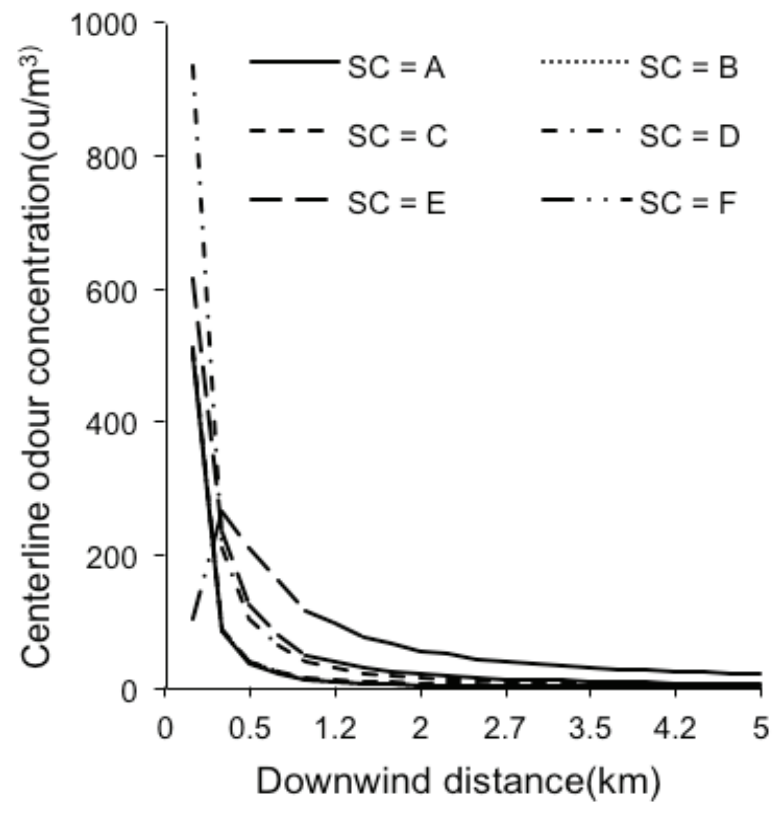

Fig. 10. Centerline odour concentrations for different stability classes (SC).

among other conditions, the absolute elasticity values were all greater than 8 . Thus the sensitivities of stability class were high. The stability class had great effect on the model prediction of both odour concentration and odour frequency. Therefore, the accuracy of determining stability class is essential for the accuracy of model predictions. One should be very careful in examining the stability class data before conducting the odour dispersion modelling to achieve the best results.

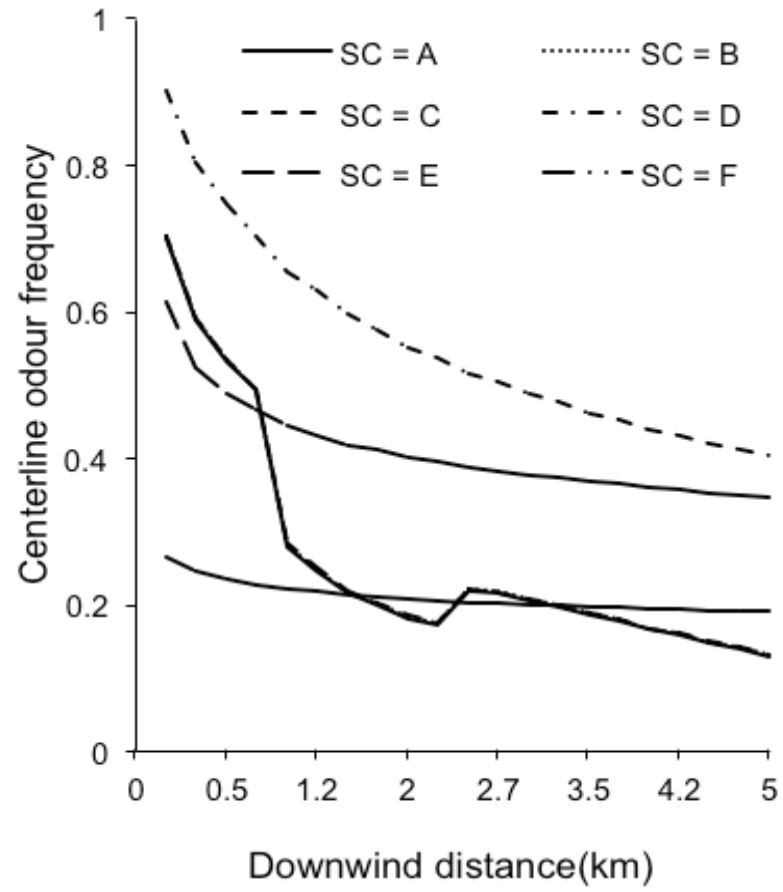

Fig. 11. Centerline odour frequencies for different stability classes (SC).

\section{Ambient temperature}

The effect of ambient temperature on odour concentration and odour frequency is shown in two aspects: plume rise calculation and PBL characterization. Figures 12 and 13 show the centreline odour concentration and odour frequency of different ambient temperatures under different stability conditions. Table 6 lists the average changes of odour concentrations and odour frequencies as well as the elasticity values. Under unstable and neutral

Table 5. Sensitivity analysis of odour concentration and frequency to stability class.

\begin{tabular}{cccccccccc}
\hline \multicolumn{2}{c}{ Stability class } & \multicolumn{4}{c}{ Concentration } & \multicolumn{3}{c}{ Frequency } \\
\hline Control & New & Ave. C & S(0.5) & S(5) & S(ave) & Ave. F & S(0.5) & S(5) & S(ave) \\
\hline A & B & 0.4 & 0.30 & 0.21 & 0.23 & 0.1 & -0.04 & 0.11 & 0.05 \\
B & A & -0.4 & -0.30 & -0.21 & -0.23 & -0.1 & 0.04 & -0.11 & -0.05 \\
B & C & 0.6 & 0.52 & 0.37 & 0.40 & 0.1 & 0.03 & 0.06 & 0.07 \\
C & B & -0.6 & -0.52 & -0.37 & -0.40 & -0.1 & -0.03 & -0.06 & -0.07 \\
C & D & 97.4 & 3.48 & 134.47 & 86.19 & 25.8 & -31.98 & 38.48 & 10.42 \\
D & C & -49.3 & 308.68 & -55.85 & -8.18 & -20.5 & 253.00 & -25.81 & 25.09 \\
D & E & 4.1 & 20.26 & 32.75 & 30.23 & -21.6 & -40.19 & -18.71 & -23.74 \\
E & D & -3.9 & -16.85 & -24.67 & -22.96 & 27.6 & 72.36 & 23.02 & 32.41 \\
E & F & 45.9 & 40.40 & 65.94 & 59.02 & -114.8 & -238.30 & -101.71 & -132.26 \\
F & E & 85.0 & 67.80 & 193.63 & 167.38 & -53.4 & -68.63 & -50.42 & -55.78 \\
\hline
\end{tabular}

Ave. C Change, \%: percentages of averaged changes of odour concentration; Ave. F Change, \%: percentages of averaged changes of odour frequency; $\mathrm{S}(0.5)$ : elasticity values calculated at downwind distances of $0.5 \mathrm{~km} ; \mathrm{S}(5)$ : elasticity values calculated at downwind distances of $5 \mathrm{~km}$. 


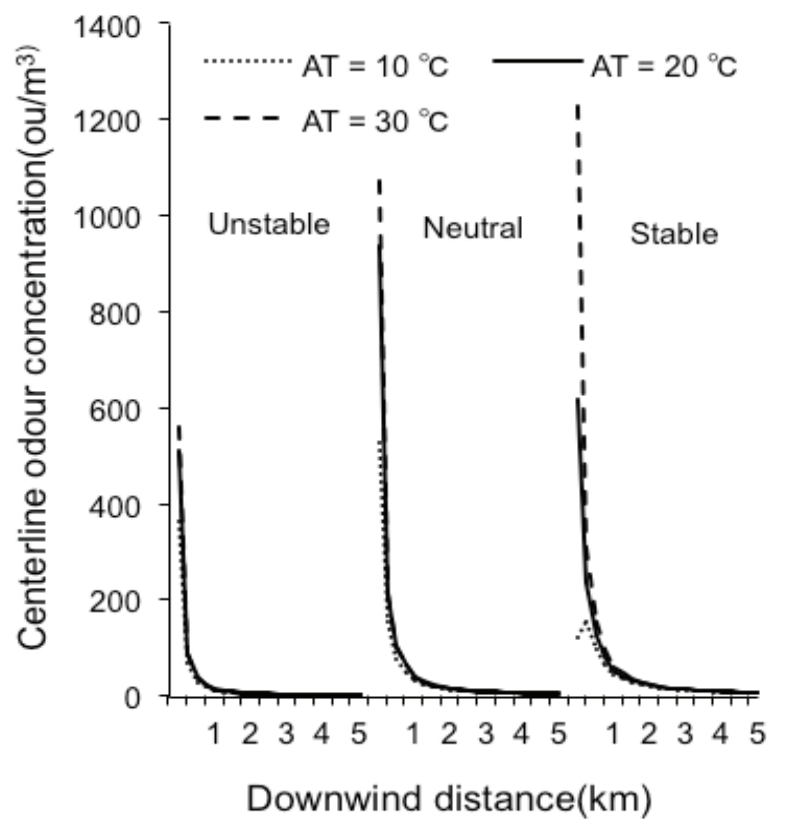

Fig. 12. Centerline odour concentrations with different ambient temperatures (AT).

conditions, the effect of increasing ambient temperature is negligible. The difference between ambient temperature and exit temperature is the determining factor on whether the plume rise is buoyancy dominated or momentum dominated. When ambient temperature is close to or larger than the exit temperature (ambient temperature $\geq 20^{\circ} \mathrm{C}$ in this simulation) under unstable and neutral conditions, the plume rise is determined by momentum rise in LODM. The effect of odour concentration and odour frequency is solely on PBL characterization. However, when ambient temperature decreased from $20^{\circ} \mathrm{C}$ to $10^{\circ} \mathrm{C}$, the plume rise changed from momentum dominated to buoyancy dominated. The average elasticity values were -0.62 and 0.46 for odour concentration and -0.21 and -0.16 for odour frequency under unstable and neutral, respectively. Under

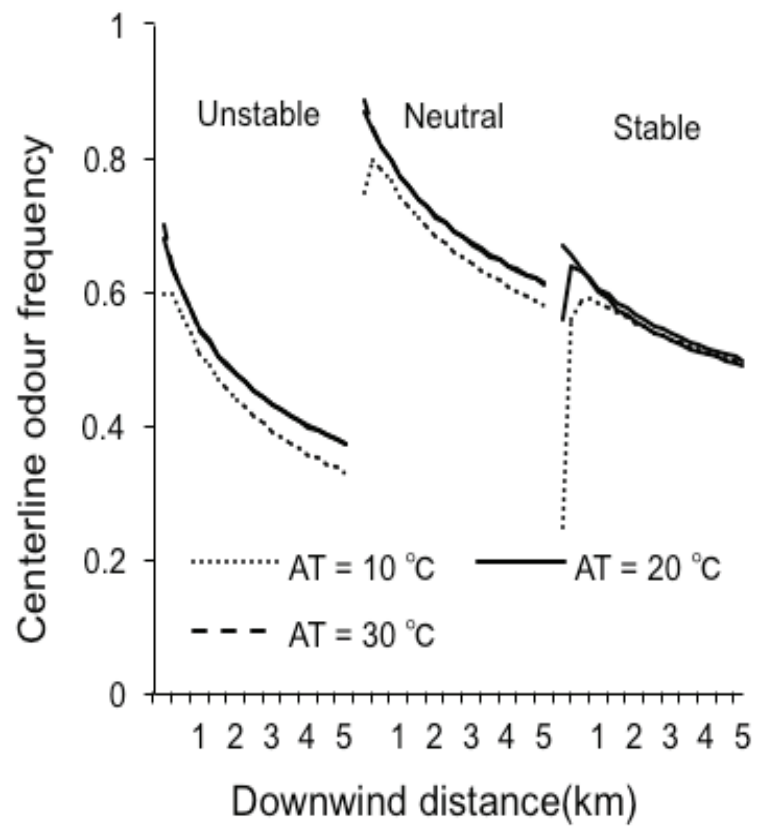

Fig. 13. Centerline odour frequencies with different ambient temperatures (AT).

stable condition, when ambient temperature decreased from $20^{\circ} \mathrm{C}$ to $10^{\circ} \mathrm{C}$, the averaged elasticity values were 0.28 for odour concentration and -0.08 for odour frequency. The sensitivity of ambient temperature was medium to model predicted odour concentration and low to medium to odour frequency. It can be also concluded that the effect of ambient temperature on plume rise contributed more on concentration and frequency results than on PBL characterization.

\section{Mixing height}

The effect of mixing height on concentration and frequency under unstable and neutral conditions comes from the concentration calculation when considering the effects of the restriction on vertical plume growth at the top of the mixing layer. From Table 7, the effect of

Table 6. Sensitivity analysis of odour concentration and frequency to ambient temperature with a control value of $20^{\circ} \mathrm{C}$.

\begin{tabular}{|c|c|c|c|c|c|c|c|c|c|}
\hline \multirow{2}{*}{ Stability } & \multirow{2}{*}{ Change, $\%$} & \multicolumn{4}{|c|}{ Concentration } & \multicolumn{4}{|c|}{ Frequency } \\
\hline & & Ave. C & $\mathrm{S}(0.5)$ & $\mathrm{S}(5)$ & S(ave) & Ave. F & $\mathrm{S}(0.5)$ & $\mathrm{S}(5)$ & S(ave) \\
\hline \multirow{2}{*}{ Unstable } & -50 & -29.0 & -0.52 & -0.64 & -0.62 & -9.9 & -0.20 & -0.24 & -0.21 \\
\hline & +50 & 4.5 & 0.00 & 0.00 & 0.00 & 0.0 & 0.00 & 0.00 & 0.00 \\
\hline \multirow{2}{*}{ Neutral } & -50 & -31.2 & -0.50 & -0.45 & -0.46 & -6.2 & -0.32 & -0.13 & -0.16 \\
\hline & +50 & 5.7 & 0.00 & 0.00 & 0.00 & 0.0 & 0.00 & 0.00 & 0.00 \\
\hline \multirow{2}{*}{ Stable } & -50 & -31.9 & -0.47 & -0.23 & -0.28 & -3.0 & -0.32 & -0.03 & -0.08 \\
\hline & +50 & 40.1 & 0.52 & 0.36 & 0.39 & -1.1 & 0.09 & -0.03 & -0.01 \\
\hline
\end{tabular}

Ave. C Change, \%: percentages of averaged changes of odour concentration; Ave. F Change, \%: percentages of averaged changes of odour frequency; $\mathrm{S}(0.5)$ : elasticity values calculated at downwind distances of $0.5 \mathrm{~km} ; \mathrm{S}(5)$ : elasticity values calculated at downwind distances of $5 \mathrm{~km}$. 
Table 7. Sensitivity analysis of odour concentration and frequency to mixing height with a control value of $1000 \mathrm{~m}$.

\begin{tabular}{|c|c|c|c|c|c|c|c|c|c|}
\hline \multirow{2}{*}{ Stability } & \multirow{2}{*}{ Change, $\%$} & \multicolumn{4}{|c|}{ Concentration } & \multicolumn{4}{|c|}{ Frequency } \\
\hline & & Ave. C & $\mathrm{S}(0.5)$ & $\mathrm{S}(5)$ & S(ave) & Ave. F & $\mathrm{S}(0.5)$ & $\mathrm{S}(5)$ & S(ave) \\
\hline \multirow{2}{*}{ Unstable } & -50 & 0.0 & 0.00 & 0.00 & 0.00 & 0.0 & 0.00 & 0.00 & 0.00 \\
\hline & +50 & 0.0 & 0.00 & 0.00 & 0.00 & 0.0 & 0.00 & 0.00 & 0.00 \\
\hline \multirow{2}{*}{ Neutral } & -50 & 0.0 & 0.00 & 0.00 & 0.00 & 0.0 & 0.00 & 0.00 & 0.00 \\
\hline & +50 & 0.0 & 0.00 & 0.00 & 0.00 & 0.0 & 0.00 & 0.00 & 0.00 \\
\hline \multirow{2}{*}{ Stable } & -50 & 0.6 & 0.02 & 0.03 & 0.03 & -1.3 & -0.05 & -0.02 & -0.03 \\
\hline & +50 & -0.3 & -0.01 & -0.01 & -0.01 & 0.6 & 0.02 & 0.01 & 0.01 \\
\hline
\end{tabular}

Ave. C Change, \%: percentages of averaged changes of odour concentration; Ave. F Change, \%: percentages of averaged changes of odour frequency; $\mathrm{S}(0.5)$ : elasticity values calculated at downwind distances of $0.5 \mathrm{~km}$; $\mathrm{S}(5)$ : elasticity values calculated at downwind distances of $5 \mathrm{~km}$.

mixing height in this manner was zero. Under stable conditions, the mixing height was used as the height of friction layer when calculating the Hogstrǒm stability index. From Table 7, the sensitivity of mixing height was low to both odour concentration and odour frequency.

\section{Radiation and cloud cover}

At daytime, in the convective boundary layer (CBL), the radiation data were used to characterize the PBL. However, in LODM, the dispersion parameters calculated for CBL were irrelevant to the stability. The effect of solar radiation will be shown on the wind profile. The results showed that the sensitivity of radiation on odour concentration and odour frequency was indifferent and can be neglected.

In CBL, when solar radiation is not available, LODM use cloud cover to estimate the solar radiation from clear sky solar radiation. Therefore, the sensitivity of cloud cover in $\mathrm{CBL}$ is as same as the solar radiation, which is negligible.
In SBL, cloud cover is an important factor in determining the Hogstrǒm stability index, and thus it might have some effects on odour concentration and odour frequency. However, the sensitivity of cloud cover is also indifferent as shown in Table 8.

\section{CONCLUSION}

The sensitivities of LODM to its input meteorological parameters were analyzed using averaged change of odour concentration and odour frequency and a defined elasticity (s). The effects of meteorological parameters on downwind odour concentrations and odour frequencies are different. The sensitivity of wind speed was from medium to high to odour concentration and low to high to odour frequency under different stability conditions. The wind direction and stability class had high sensitivity on both odour concentration and odour frequency. The sensitivity of ambient temperature was medium to model

Table 8. Sensitivity analysis of odour concentration and frequency to cloud cover with a control value of 0.5 in SBL (Stable Boundary Layer).

\begin{tabular}{cccccccccc}
\hline \multirow{2}{*}{ Change, $\%$} & \multicolumn{3}{c}{ Concentration } & \multicolumn{3}{c}{ Frequency } \\
\cline { 2 - 8 }-100 & Ave. C & $\mathrm{S}(0.5)$ & $\mathrm{S}(5)$ & $\mathrm{S}(\mathrm{ave})$ & Ave. F & $\mathrm{S}(0.5)$ & $\mathrm{S}(5)$ & $\mathrm{S}(\mathrm{ave})$ \\
\hline-80 & 0.0 & 0.00 & 0.00 & 0.00 & 0.0 & 0.00 & 0.00 & 0.00 \\
-60 & 0.0 & 0.00 & 0.00 & 0.00 & 0.0 & 0.00 & 0.00 & 0.00 & 0.00 \\
-40 & 0.0 & 0.00 & 0.00 & 0.00 & 0.0 & 0.00 & 0.00 & 0.00 & 0.00 \\
-20 & 0.0 & 0.00 & 0.00 & 0.00 & 0.0 & 0.00 & 0.00 & 0.00 \\
20 & 0.0 & 0.00 & 0.00 & 0.00 & 0.0 & 0.00 & 0.00 & 0.00 \\
40 & 0.0 & 0.00 & 0.00 & 0.00 & 0.0 & 0.00 & 0.00 & 0.00 \\
60 & 0.0 & 0.00 & 0.00 & 0.00 & 0.0 & 0.00 & 0.00 & 0.00 & 0.00 \\
80 & 0.0 & 0.01 & 0.00 & 0.00 & 0.0 & 0.00 & 0.00 & 0.00 \\
100 & 0.0 & 0.01 & 0.01 & 0.01 & 0.0 & 0.00 & 0.00 \\
\hline
\end{tabular}

Ave. C Change, \%: percentages of averaged changes of odour concentration; Ave. F Change, \%: percentages of averaged changes of odour frequency; $\mathrm{S}(0.5)$ : elasticity values calculated at downwind distances of $0.5 \mathrm{~km} ; \mathrm{S}(5)$ : elasticity values calculated at downwind distances of $5 \mathrm{~km}$. 
predicted odour concentration and low to medium to odour frequency. The sensitivity of mixing height is low while it is indifferent of solar radiation and cloud cover. The meteorological parameters in an order of decreasing importance would appear to be stability class, wind direction, wind speed, ambient temperature, cloud cover, mixing height, and radiation. The sensitivity analysis of LODM output odour frequency to Pasquill-Gifford stability class showed unusual pattern. Odour frequency decreased when stability changed from neutral to more stable. Although, this finding can be explained from the model theory's point of view and was supported by an observation, more work needs to be done to have more supporting evidence of this phenomenon as well as to have more clear view on the effect of stability class on odor frequency.

\section{ACKNOWLEDGEMENT}

This research has been funded by the CIHR Strategic Training Program in Public Health and the Agricultural Rural Ecosystem (PHARE), the Canadian Centre for Health and Safety in Agriculture, and CIHR Partner Institutes including the Institute of Health Services and Policy Research, Institute of Circulatory and Respiratory Health, Institute of Infection and Immunity, and the Institute of Population and Public Health.

\section{REFERENCES}

Chastain, J.P and F.J. Wolak. 2000. Application of a Gaussian plume model of odor dispersion to select a site for livestock facilities. In Proceedings of the Water Environment Federation, Odors and VOC Emissions, 745-758. Anaheim, CA. October 14-18.

De Bree, F and H. Harssema. 1987. Field evaluation of a fluctuating plume model for odours with sniffing teams. In Environmental Meteorology, Eds. K. Grefen and J. Löbel, 473-486. Dordrecht, Netherlands: Kluwer Academic Publishers.

Faulkner, W.B., B.W. Shaw and T. Grosch. 2008. Sensitivity of two dispersion models (AERMOD and ISCST3) to input parameters for a rural-level area source. Journal of Air \& Waste Management Association 58: 1288-1296. http://dx.doi.org/10.3155/1047-3289.58.10.1288

Guo, H., C. Lague, J.R. Feddes, W. Dehod, J. Agnew and S. Pang. 2005. Community odour monitoring using local resident-observers. Final report submitted to Saskatchewan Department of Agriculture, Food and Rural Revitalization, Sask Pork, and Albert Livestock Development Fund. Saskatoon, SK: Department of Agricultural and Bioresource Engineering, University of Saskatchewan.
Guo, H., W. Dehod, J. Feddes, C. Laguë and I. Edeogu. 2006. Monitoring odour occurrence in the vicinity of swine farms by resident observers- Part II: Impact of weather conditions on odour occurrence. Canadian Biosystems Engineering 48: 23-29.

Guo, H., L.D. Jacobson, D.R. Schmidt and R.E. Nicolai. 2001. Calibrating INPUFF-2 model by residentpanelists for long-distance odour dispersion from animal production sites. Applied Engineering in Agriculture 17(6): 859-868.

Högström, U. 1972. A method for predicting odour frequencies from a point source. Atmospheric Environment 6: 103-121. http://dx.doi.org/10.1016/ 0004-6981(72)90125-4

Horwedel, J.E., R.J. Raridon and R.Q. Wright. 1992. Automated sensitivity analysis of an atmospheric dispersion model. Atmospheric Environment Part A 26(3): 1643-1649. http://dx.doi.org/10.1016/09601686(92)90063-Q

Mussio, P., A. W. Gnyp and P. F. Henshaw. 2001. A fluctuating plume dispersion model for the prediction of odour-impact frequencies from continuous stationary sources. Atmospheric Environment 35(16): 2955-2962. http://dx.doi.org/10.1016/S1352-2310(00)00419-2

Smith, R.J. 1993. Dispersion of odours from ground level agricultural sources. Journal of Agricultural Engineering Resources 54: 187-200. http://dx.doi.org/10.1006/jaer.1993.1013

USEPA. 2000. Meteorological Monitoring Guidance for Regulatory Modeling Applications. Research Triangle Park, NC: U.S Environmental Protection Agency.

USEPA. 2004. AERMOD: Description of Model Formulation. Research Triangle Park, NC: U.S Environmental Protection Agency.

Xing, Y., H. Guo, J. Feddes, Z. Yu, S. Shewchuck and B. Predicala., 2007. Sensitivities of four-air dispersion model to climatic parameters for swine odour dispersion. Transactions of the ASABE 50(3): 10071017. http://dx.doi.org/10.13031/2013.23141

$\mathrm{Yu}, \mathrm{Z}$., H. Guo and C. Laguë. 2011a. Development of a livestock odor dispersion model (LODM): Part I. Model theory and development. Journal of Air \& Waste Management Association 61: 269- 276. http://dx.doi.org/10.3155/1047-3289.61.3.269

Yu, Z., H. Guo and C. Laguë. 2011b. Development of a livestock odor dispersion model (LODM): Part II. Evaluation and validation. Journal of Air \& Waste Management Association 61: 277- 284. http://dx.doi.org/10.3155/1047-3289.61.3.277 